\title{
Situational Factors Influencing Employee Theft in Supermarket Outlets: A Survey of Kisumu City, Kenya
}

\author{
Rebecca J. Kibet, Dr. Wycliffe Nyachoti, Dr. Pia Okeche. \\ Kisii University, Department Of Criminology and Security Studies, School of Law, \\ Address: P.O Box 408-40200. Kisii
}

\begin{abstract}
Employees' theft is an act of stealing, use, or misuse of an employer's asset without his or her consent. Despite the security surveillance measures taken by the supermarket retail outlets, these businesses are yet to have any significant reduction in the theft cases in the supermarkets. The study aimed to establish the effects of situational factors on employees' theft in the supermarket outlets within Kisumu City, Kenya. The objectives of the study were: to assess the effect of prevailing opportunity to steal on employees' theft, to examine the contribution of organizational values and culture to employees' theft, to establish how employees' attributes contribute to theft and to determine the effect of job dissatisfaction on employees' theft in the supermarkets within Kisumu City. The study adopted a cross-sectional qualitative research design. The study was informed by Rational Choice Theory developed by Siegel and McCormick, 2006, and Equity Theory of Employee Motivation established by Adams. In this study, a qualitative survey design was adopted. A convenient sampling technique was used to sample 10 managers, 10 cashiers, and 10 subordinate staff from 10 supermarket outlets within Kisumu City out of the target population of 400 employees. The analyzed demographic data were presented in frequency tables and charts while qualitative data was analyzed thematically. The study revealed that the availability of opportunity to steal is one of the main reasons why employees working in supermarkets indulge in workplace theft. This occurs due to the use of weak monitoring systems to curb theft-related cases by supermarket managers. Besides, the study established that staff who steal from the workplace do not recognize the formal organizational values and practices imposed by the management. As a result, poor organization values and cultural practices have a meaningful effect on the employees in the supermarkets thus influence employees' theft. This, therefore, means that organizational values guide the employees on what is right or wrong and what is most important in life, hence greatly controls their behavior in the organizations. Moreover, employees with negative personal attributes for instance were more likely inclined towards engaging in criminal behavior such as theft than those who did not. The study recommends that future researchers should conduct a comparative study on the causes of job dissatisfaction and how it contributes to employees' theft. Lastly, the study recommends that further research should be conducted on the overall perception of the workplace theft by employees across the different organizations.
\end{abstract}

Key Words: employees, theft, supermarkets, business, opportunity, organization values

DOI: $10.7176 /$ RHSS/10-18-09

Publication date:September $30^{\text {th }} 2020$

\section{Background to the Study}

Employee theft is defined as theft by an employee or his or her accomplice of anything of value from the respective employer. The methods of this kind of theft include stealing merchandise, stealing money, holding receipts to demonstrate that stolen goods have been paid for, canceling a sale or making a no-sale after a client has paid and pocketing the money, overloading, short-change, stuffing coupons, credits for non-existent returns and sliding product through the lane without charge (Knežević, et al., 2016).

In America, the light-fingered employees cost the superstores more than the shoplifters do. The four months from October through January is the time when these retail stores see not just their biggest sales volume of the year but also the most returns on investment. Unfortunately, these same four months account for about half of all annual shrinkage in their overall financial returns. The shrinkage, made up of the account of all the missing goods from shoplifting and other causes, cost U.S. retailers about 42billion dollars yearly. This is according to the latest Global Retail Theft Barometer, an annual industry study by Checkpoint Systems, an inventory management firm. Shoppers pay the price for such theft, which is majorly caused by the employees of the said stores. The cost of such mysteriously vanishing goods comes to an average of 403 dollars per U.S. household. This is so serious that the theft by the employees accounts for $43 \%$ of the lost revenue (Anne Fisher and Ernie Deyle, 2019).

Through the examination of literature that relates to theft in the workplace, a key motivational characteristic that has been addressed by the research concerns the commonly perceived attitude that feelings of being treated unfairly can lead to staff seeking opportunities to steal (Gold, 2016). Another central thing that is suggested by researchers to relate to the practice of staffs' theft and criminal behavior, escalates from morally and ethically deficient actions (Lind and Kääriäinen, 2018). Employee theft is also said to be driven by other motive factors such as an opportunity 
or greed, and need rationalization (Eck, 2019). This provides the ground for this study on employee theft. Furthermore, no study had been conducted on supermarket theft within Kisumu city, thus there exists a research gap that the study on the situational factors influencing employees' theft in the supermarket outlets within Kisumu city aimed to fill.

\section{Statement of the Problem}

Retail Market business, and specifically, Supermarket business, is one of the major sectors that experience exponential growth in many countries and Kenya as well. In Kenya, this sector has been oscillating between position one and three of the fastest-growing segments of the economy in the past few years, (Hansen, et al. 2018). Aila, (2013) observed that the sector registered the fastest growth, a 7.5\% upswing in 2013. The Kenya Economic Survey (KES) also observed this growth. It has, therefore, been considered as performing better than many financial services, manufacturing, building and construction, agriculture, transport, and communication sectors of the same economy under the prevailing circumstances.

Despite this sector registering an upsurge growth, it is a sector reeling under the burden of losses through a complex network of criminals who have mastered the art of dodging established payment control systems. Generally, supermarket outlets in the country are currently estimated to be losing up to KSh3 billion annually through various means. Chief among them is internal employee theft (Wangari, 2012). Moreover, the sector experiences struggle to arrest runaway, internally coordinated theft by both cashiers and Subordinates employees in what could be an established network of organized crime. Although mechanisms for prevention and tackling of supermarket related theft has been put in place, in Kenya supermarkets have estimated losses incurred through theft and shoplifting being worth Kshs 3 billion yearly, (Kibacia and Siror, 2017). Retail Outlet employee theft is also said to be driven by other motive factors such as an opportunity or greed, and need rationalization (Eck, 2019).

This study endeavors to shed more light on supermarket theft, a socio-economic crime, and a security problem that has nagged security and loss prevention experts for many years. It thus provides the ground for this study on employee theft since no such study had been conducted on supermarket theft within Kisumu City. As a result of no similar study in the study area, there exists a research gap that the current study on the situational factors influencing employees' theft in the supermarket's outlets within Kisumu city aims to bridge.

\section{General Objective of the Study}

The general objective of this study was to establish the effects of situational factors on employees' theft in the supermarket outlets within Kisumu city, Kenya.

\section{Specific Objectives of the Study}

i. To determine the effect of the prevailing opportunity to steal on employee theft at supermarket outlets in Kisumu City, Kenya.

ii. To examine the contribution of organizational values and culture to the theft of employees at supermarket outlets in Kisumu City, Kenya.

iii. To establish how the personal attributes of employees affect employee theft at supermarket outlets in Kisumu city, Kenya.

iv. To determine the contribution of job dissatisfaction on employee theft at supermarket outlets in Kisumu city, Kenya.

\section{Research Questions of the Study}

i. How does the prevailing opportunity to steal affect employee theft at supermarket outlets in Kisumu city, Kenya?

ii. What is the contribution of organizational value and culture on employee theft at supermarket outlets in Kisumu city, Kenya?

iii. How do personal attributes of employees affect employee theft at supermarket outlets in Kisumu city, Kenya?

iv. How does job dissatisfaction lead to employee theft at supermarket outlets in Kisumu City, Kenya?

\section{Justification of the Study}

Employee theft in supermarket outlets is a socio-economic crime that was for a long time assumed to be of no significance. According to Hansen, et al., (2018) many people tend to think that due to the availability of technologies such as CCTV, both the staff and customers are scared of picking any item from the supermarket 
shelves. This is not so since many supermarket outlets had suffered losses not only related to external factors, but also to internal factors, which include employee theft practiced by the staff and managers, (Hansen, et al., 2018). The study targeted thirteen supermarkets however, due to time constraints; the focus was made on ten major supermarket outlets in Kisumu city. The targeted supermarkets formed a good representative population of the supermarket outlets in the entire city. The study on employees' theft on supermarket outlets in Kisumu is a new study and the findings of this research can be used to bridge the existing research gap on this subject. Besides, future researchers would use the findings as reference material for future studies on employee theft in businesses. The findings also would provide a further understanding of the rational choice theory and staff behavior by providing answers to various research questions raised in the paper. The findings would also provide recommendations to managers of the supermarket outlets to enhance efficient controls.

\section{Scope of the Study}

The study was confined to the situational factors influencing employees' theft in the supermarket outlets in Kisumu City, Kenya.

\section{Assumptions of the Study}

The study was guided by the following assumptions:

i. The criminal acts are inherent and some supermarket staffs continue to commit internal theft despite being paid well and even with the surveillance controls.

ii. The motivating factor for the staff internal theft depends on the available opportunities to steal with less pain.

\section{Limitations of the Study}

The primary data that were used for the research were the interview responses from respondents; managers, cashiers, and the subordinate staff including cleaners, shelf keepers, and watchmen. Some of the interviewees were hesitant to answer the questions for fear that they could be victimized from the study findings. This had the potential for giving biased information. Due to the smaller sample (representative), the findings could not accurately represent the entire population across the supermarkets. A convenient sampling technique was used to make sure the sampled population would give the right information to the research questions. Thirdly, the researcher experienced some financial limitations in terms of the cost for transcription; however, by adhering to the scope of the study, cost-effectiveness was enhanced.

\section{Conceptual Framework}

This conceptual framework is a diagrammatic illustration that indicates the interaction among the moderating, independent, and dependent variables in the research. This framework had the prevailing opportunity to steal, organizational values/culture, employee personal attributes, and job dissatisfaction being the independent variables while employee theft was the dependent variable. 


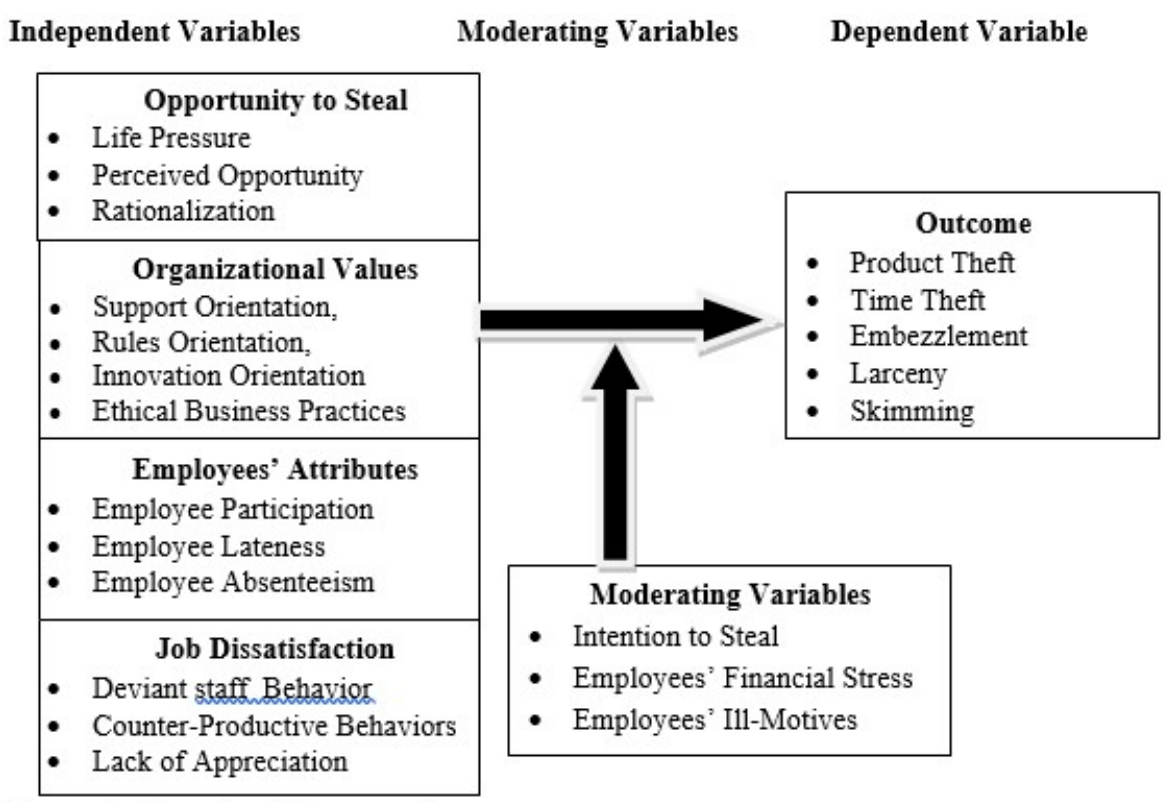

Figure 1: Conceptual Framework

Source - Adapted from Scoones (2018)

Theoretical Framework of the Study

\section{LITERATURE REVIEW}

This represented a literature review on the factors that influence employees' theft in the supermarkets, which is informed by Rational Choice Theory and Equity Theory of Employee Motivation. Equity Theory was established by J. S. Adams in 1963, it attempts to explain relational satisfaction in terms of perceptions of fair or unfair distributions of resources within interpersonal relationships. Equity Theory proposes that employees' who feel under-rewarded or even over-rewarded, might experience distress and that also could lead to them making efforts to try to restore or equalize equity within the relationship.

Rational Choice Theory

The rational choice theory founded by Siegel and McCormick, 2006, guides this study. The theory of rational choice is a theory based on the basic principles of classical criminology which hold that people choose their actions liberally and are guided by pain avoidance and pleasure-seeking. Individuals evaluate their choice of actions according to the ability of each option to produce benefit, pleasure, and happiness. Rational choice provides insight into why individual criminals choose to commit specific crimes; people choose to commit criminal offenses because they can be enticing, simple, enjoyable, and fun. This theory's central premise is that people are rational beings whose behavior can be controlled or modified through fear of punishment. The rational choice theory applies to the study since it illustrates the connectivity between the choices and decisions made by an individual before he or she commits a crime. It thus shows that every criminal act committed or likely to be committed by a prospect criminal is first thought of and its benefits evaluated. It also illustrates the causes or factors that result in a criminal act.

Equity Theory of Employee Motivation

The term 'equity' in the employee context is when an individual staff considers himself or herself as fairly treated if he/she believed that the ratio of his/her work inputs to remunerative outcomes is equal to those around him; such as other employees in the workplace. This is relevant in the workplace scenario as an experiment found that "...subjects who were equitably paid did not steal, whereas those who were underpaid did steal" (Giacalone and Greenberg, 2017). Statistics show that theft in the workplace is more common than people think as the Daily Express (March 2013) discovered that over 50\% of employees have admitted to stealing from their employers at some point. One area of concern for retailers is the impact of employee theft on retailing profit margins and operations. The application of the theory could shed some light on the problem and possibly offer some assistance to retailers. The theory has a model and a series of propositions developed. The propositions are open to empirical verification to form the basis for a research stream on retail employee theft. The model incorporates certain individual difference factors that are likely to influence intentions to engage in retail theft. 


\section{Critical Review of Literature}

From the past studies, it can be critically concluded that improved organizational performance does not result only from the number of human resource practices alone, but also from effective implementation of efficient control systems, which requires the use of effective management skills (Caulkin, 2016). Research on retail store staff in the private sector in Canada and the United States of America demonstrated the importance of leadership and management skills for successful performance (Buchan, 2018). Research has shown that management role when correctly handled contribute to job satisfaction in the long and medium terms.

The past studies have not laid a lot of interest in considering staff performance in retail stores. The major emphasis is on training and development, reward schedules, motivation, and promotion; which are regarded as fundamental tools in affecting the performance of an organization; but control systems are equally important. Managers of retail stores, therefore, need leadership and management skills to ensure that their staffs perform according to recognized standards and are motivated to work; thus averting theft. Researchers, however, have not yet put as much emphasis on this as it ought to be and as such management positions in the retail stores are often occupied by untrained managers based barely on work experience in different departments, particularly at lower cadres (Lee, Kim, and Park, 2013).

They can help enhance the satisfaction, motivation, and productivity of their employees in the organization by gainful staff development, which is observed as having tangible benefits for the employees and organization as a whole. It helps in establishing a reward system that optimizes the efforts and contribution of leaders and employees to the general performance of their Organization. The propagation of efficient controls and performance systems is motivated by a broad range of concerns including promotions, motivation, training, and the development of adequate competence and expertise (Cleveland, Murphy, and Williams, 2017).

To achieve and maintain the survival and success of any organization, its managers do not only have to acquire appropriate people to resource it but they also need to train and develop their employees (Pfeffer, and Veiga, 2009). Since a motivated staff and working control system helps to identify the training and development of staff needs, organizations should have an effective staff appraisal. This would boost performance.

In the retail stores' sector, a complete functional job analysis not only outlines the essential tasks of the job, but also identifies the critical knowledge, skills, and abilities necessary to perform the tasks and determines the physical demands that are directly linked to the tasks to enhance employee motivation and their subsequent satisfaction. When a job analysis incorporates all this information, duplication of effort is eliminated while specific job information is easier to keep current for better staff satisfaction.

This, however, did not give satisfactory results on how it influenced performance nor its effect on the everincreasing theft in the supermarkets in the country. These justify the need for research on the situational factors that influence employee theft in supermarkets and how this affects the performance of the stores. It would be vital to ensure continuous evaluation of staff productivity, motivation, and commensurate remuneration to avert the criminal and insecurity activities by staff through responsive supermarket management.

Another study in Nairobi Kenya by Nzuve, and Njeru, (2013) on the performance of staff in the city council through a longitudinal survey found out that some raters or managers want to describe themselves as hard and perfectly based managers. As a result, they avoid giving a high rating even if the staff performance is worthy. Rather than giving extreme poor or good grades, there is a tendency on the part of some raters to evaluate all rates as average scores even if performance varies. This, however, had nothing to do with surveying staff motivation in retail stores and how this would lead to their satisfaction, neither was it in Kisumu where such theft is rampant; hence the need for this current study.

\section{RESEARCH METHODOLOGY}

This section summarises the research methodology employed in the study. It thus focuses on the research design; study area, target population, sample size and sampling procedures, research instruments, and data collection procedures and data analysis; as well as the research ethical considerations which the researcher adhered to in the study.

\section{Study Area}

This study was conducted in Kisumu city. Kisumu is the principal city of western Kenya, the capital of the Nyanza Region and headquarters of Kisumu County. It is situated at an altitude of $1131 \mathrm{~m}$ with a population of 600,000 
(KNBS, 2019 census). The area was best chosen for the study due to upsurge in supermarket outlets and associated employee theft.

\section{Research Design}

The study adopted a qualitative survey design. It involved the collection of information by conducting face-face interviews to all the sampled respondents. The design contributed towards achieving the primary purpose of the research which was to examine the various situational factors which contribute to employees' theft in supermarket outlets in Kisumu city. It was advantageous because it permitted the researcher to summarize the characteristics of different groups and measure their attributes, opinions, habits, or any of the variety of education or socioeconomic issues in workplace theft (Nardi, 2018).

\section{Target Population}

The target population refers to all the members of a real or hypothetical set of people, events, or objects from which the scholar wishes to generalize the results of a research study (Nardi, 2018). This study targeted 13 major supermarket outlets within Kisumu city. The population consisted of 13 supermarket managers, 132 cashiers, and 255 subordinates making a population of 400 people. However due to the intensity of the survey primary data were collected from a representative sample of 30 respondents composing of 10 managers, 10 cashiers, and 10 subordinate staff. In this study, the data from the cashiers and the Subordinate staffs i.e. the shelf keepers, cleaners, and watchmen were obtained through interview schedule A. However, the responses from the supermarket managers were obtained through separate interview schedule B. The study focused on the 10 major supermarkets in Kisumu city. Secondly, studying the bigger proportion of established supermarkets gave a good representation of the population being studied, thus making it easy to make valid informed conclusions from the research study carried out.

\section{Sampling Frame and Sampling Techniques}

The basic rule on accessible population size is that the larger the population size, the better the results of the study. Sample sizing, however, is a complex matter, with many considerations, Krejcie and Morgan, (1970). The researcher used a convenient sampling technique to sample the respondents. This was of value since the participants were chosen concerning research questions which resulted in quality findings and thus recommendations.

Table 1: Sampling Frame

\begin{tabular}{lccc}
\hline \multicolumn{1}{c}{ Category of Respondents } & $\begin{array}{c}\text { Targeted } \\
\text { Population }\end{array}$ & $\begin{array}{c}\text { Sampled } \\
\text { Population }\end{array}$ & Rate (\%) \\
\hline Managers & 13 & 10 & $100.0 \%$ \\
Cashiers & 132 & 10 & $100.0 \%$ \\
$\begin{array}{l}\text { Subordinate Staffs (Shelf Keepers, } \\
\text { Cleaners and Watchmen) }\end{array}$ & 255 & 10 & $100.0 \%$ \\
Total & 400 & 30 & $100 \%$ \\
\hline
\end{tabular}

Source: Field Data 2019.

This study was conducted among the targeted thirteen supermarkets in Kisumu city. These included; Nidhi, Nakumatt Mega-City, Nakumatt Mega-plaza, Kondele Tumaini, Roundabout Tumaini, Uchumi, Khetia, Ukwala, Naivas, Kondele Choppies, Yatin, Raia and Tuskys. There was an equal representation of employees across the sampled supermarkets.

\section{Data Collection Instruments}

The data collection methods are the sources and methods used to collect data to be analyzed, from which conclusions are drawn and recommendations made. Primary data was obtained through researcher-administered interview schedules while the secondary data was borrowed from the literature review. The interview schedules were of two sets one: set A for the cashiers together with the Subordinate staff (the shelf keepers, cleaners, and the watchmen) and set B for the 10 supermarket outlet managers in Kisumu city targeted in the study.

The sets of interview questions for the supermarket Cashiers together with the Subordinate staff and managers used in the interview schedules administered by the researcher were built around the four study objectives. The interview schedules sought to enhance the objectivity of the responses as much as possible. The interview 
schedules permitted a qualitative approach using open-ended and semi-structured questions targeting a wider scope of staff responses from the target population.

\section{Validity of the Research Instruments}

Validity is defined as the accuracy and meaningfulness of inferences which are based on the research results Bryman, (2016). To check on content validity any blank spaces, inaccurate responses, inconsistencies indicating ambiguity or lack of clarity, and items found to elicit this kind of reaction during the pilot study were modified or removed. To ensure that the themes covered a broad range of areas within the concept under study, the researcher ensured that items sampled from all of the domains were completed and the content was adequately covered in the interview.

\section{Data Collection Procedures}

A research permit was sought from the school of postgraduate studies of Kisii University that authorized the researcher to visit the targeted supermarkets. A research authorization letter from NACOSTI was also obtained upon approval by the university. To administer the interview schedules effectively, a personal visit to all the selected supermarkets was made. The researcher presented an introduction letter to the respondent and then explained the purpose of the research. The interview schedules were administered by the researcher and two research assistants in person to enhance the objectivity of the responses in the study.

\section{Methods of Data Analysis}

The demographic data were presented in frequency tables and charts while the findings to the research were analyzed qualitatively by narrative analysis of the themes. A qualitative correlation analysis was done to determine the relationship between the independent and dependent variables. This Qualitative data analysis involved the validation, identification, examination, and interpretation of patterns and themes in the textual data and determining how these patterns and themes helped answer the research questions in the study.

According to Tracy (2019), the qualitative method is a collection, analysis, and interpretation of comprehensive narrative, symbolic, and visual data to gain insight into a particular phenomenon to the researcher. This technique gives a lot of meaning to the data. It especially applies to data that is not very numerical in presentation and not very generalized in approach to the other theft cases. The analyzed data then becomes useful.

\section{DATA ANALYSIS, INTERPRETATION AND DISCUSSION}

This section presents the qualitative analysis and interpretation. It begins with demographic information of the respondents such as gender, age, marital status, education level and the duration of work for supermarket staff has been presented first. This is followed by the presentation of the research findings based on the study objectives on the effect of prevailing opportunity to steal, organizational values/culture, employee personal attributes, and job dissatisfaction. The qualitative data were analyzed using a thematic analysis approach to draw useful conclusions from the study in the supermarket outlets.

\section{Interviewees' Response Rate}

An in-depth interview was conducted on all the sampled study participants. The response rate is also known as the completion rate is the number of people who complete a survey compared to the number of people sampled in the study. It is determined by considering the unreachable participants who were not represented in the collected data (Saunders et al., 2016). All the two sets A and B of the interviews (audio records) were transcribed and then analyzed since they were researcher administered thus giving a $100 \%$ response rate.

Among the targeted 400 supermarket cashiers and subordinate staff from 13 supermarkets in Kisumu, the qualitative data were drawn from 30 respondents (representatives) within the 10 major supermarket outlets in Kisumu City. The sample of 30 respondents was considered because it could give a reliable representation for accurate generalization of the study findings on the other major supermarkets countrywide.

Table 2: Interviewees' Response Rate

\begin{tabular}{ccccc}
\hline $\begin{array}{l}\text { Interview Schedules } \\
\text { To Respondents }\end{array}$ & Cashiers & $\begin{array}{c}\text { Subordinate } \\
\text { Staffs }\end{array}$ & $\begin{array}{c}\text { Supermarket } \\
\text { Managers }\end{array}$ & Total \\
\hline No. Sampled & 10 & 10 & 10 & 30 \\
No. Interviewed & 10 & 10 & 10 & 30 \\
\% Response Rate & $100 \%$ & $100 \%$ & $100 \%$ & $100 \%$ \\
\hline
\end{tabular}

Source: Field Data 2019. 
Demographic Information of the Interviewees (Cashiers and Subordinate staff)

The demographic characteristics of the interviewees were summarized in figure 2 below indicates that $60.00 \%$ and $40.00 \%$ were male and female supermarket cashiers respectively. Similarly, among the subordinate staff interviewed, $70.00 \%$ and $30.00 \%$ were male and female respectively. The majority of the respondents were males, this meant that the gender distribution of the staff was slightly fair in the supermarket's outlets.

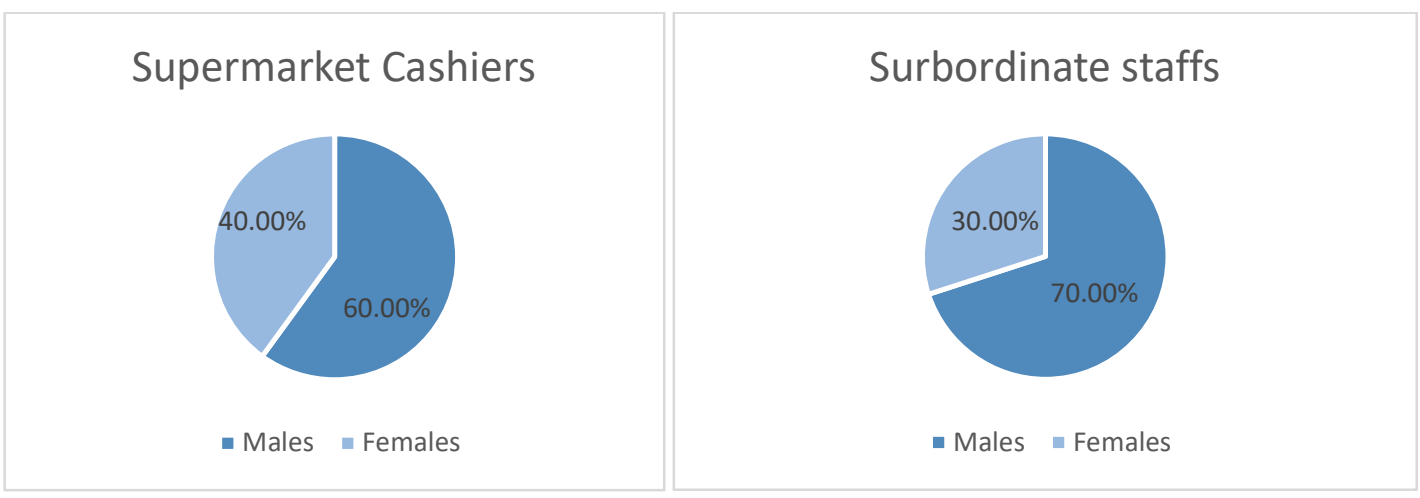

Figure 1: Gender of Cashiers and Subordinate Staffs

Source: Field Data 2019.

The gender considerations of the cashiers and subordinate staff were relatively fair in the 10 supermarkets selected for the study. This implies that the human resource policies of the supermarkets adhered to equitability across the gender. This could be as a result of affirmative action in the labor market as provided for by the International Labor Organizations and ratified by the Ministry of Labor and Resource Development in Kenya.

Table 3: Age of the Supermarket Cashiers and the Subordinate Staffs Interviewed Age of the Cashiers \& Subordinate Staffs

\begin{tabular}{llcccc} 
& & $\mathbf{1 8 - 2 5}$ years & $\mathbf{2 6 - 3 5}$ years & $\begin{array}{c}\text { 36 years and } \\
\text { above }\end{array}$ & $\begin{array}{c}\text { Total } \\
\end{array}$ \\
& Male & 1 & 3 & 2 & $\mathbf{6}$ \\
Total Cashiers & Female & 2 & 1 & 1 & $\mathbf{4}$ \\
& & $\mathbf{3}$ & $\mathbf{4}$ & $\mathbf{3}$ & $\mathbf{1 0}$ \\
Subordinate Staffs & Male & 2 & 3 & 2 & $\mathbf{7}$ \\
Total & Female & 1 & 2 & 0 & $\mathbf{3}$ \\
\hline
\end{tabular}

Source: Field Data 2019.

The interviewed staffs were asked "What is your age Bracket?" Their responses were thus presented in table 3. The study established that 4 supermarket cashiers and 5 Subordinate staffs were aged between (26-35) years. In addition, the interviewees aged between (18-25) years were 3 cashiers and 3 Subordinate staffs. Lastly, a total of 3 cashiers and 2 Subordinate staffs were over 36 years. It could thus be seen that a majority of the cashiers and the Subordinate staffs interviewed were mid-aged in the supermarkets surveyed. This implies that that the rigorous nature of the workload in these retail stores demanded energy available in the youth and middle-aged staffs. 
Table 4: Marital Status of the Supermarket Cashiers and Subordinate Staffs

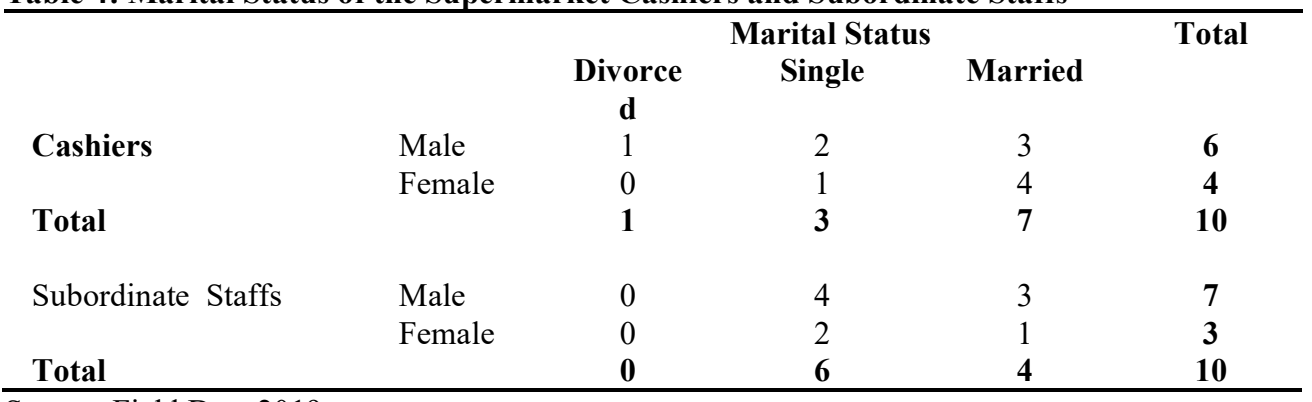

Source: Field Data 2019.

Based on the question "What is your marital status?" table 4.4 above shows the responses of interviewees. Findings indicate that 1 cashier and 0 Subordinate staffs were divorced, 3 cashiers and 6 Subordinate staffs were single. However, 7 cashiers and other 4 Subordinate staffs were married. The data here showed a social inclination towards upholding marriage institutions in the supermarkets, which could most probably reflect the social structure of the population within the city and its environs. This could also explain the reason many cases of these thefts generally involve male staffs due to the socio-economic pressures in response to the family responsibilities (Dalton, 2018).

Table 5: Educational Level of Supermarket Cashiers and Subordinate Staffs

\begin{tabular}{|c|c|c|c|c|c|}
\hline & & \multicolumn{3}{|c|}{ Educational Level } & \multirow[t]{2}{*}{ Total } \\
\hline & & Primary & $\begin{array}{c}\text { Secondar } \\
\mathrm{y}\end{array}$ & $\begin{array}{l}\text { College/ } \\
\text { Universit }\end{array}$ & \\
\hline Cashiers & Male & 0 & 1 & $\begin{array}{l}\mathrm{y} \\
5 \\
2\end{array}$ & 6 \\
\hline Total & Female & $\begin{array}{l}0 \\
\mathbf{0}\end{array}$ & $\begin{array}{l}2 \\
3\end{array}$ & $\begin{array}{l}2 \\
7\end{array}$ & $\begin{array}{c}4 \\
10\end{array}$ \\
\hline $\begin{array}{l}\text { Subordinate Staffs } \\
\text { Total }\end{array}$ & $\begin{array}{l}\text { Male } \\
\text { Female }\end{array}$ & $\begin{array}{l}2 \\
0 \\
\mathbf{0}\end{array}$ & $\begin{array}{l}4 \\
3 \\
3\end{array}$ & $\begin{array}{l}1 \\
0 \\
7\end{array}$ & $\begin{array}{r}7 \\
3 \\
10\end{array}$ \\
\hline
\end{tabular}

Source: Field Data 2019.

With the regard to the question, "What is your level of education?" The interviewees' responses were presented in table 5 for both the supermarket cashiers and their Subordinate counterparts. Findings revealed that majority of the cashiers had college education while majority of subordinate staff had secondary education. The level of education should be put into consideration in employee selection in the supermarkets to stem employee theft through inductive training as this could help make the staffs have a sense of ownership and thus enhance a sense of responsible business management in the workplace (Rene, 2019).

Table 6: Duration of Work at the Supermarkets

\begin{tabular}{|c|c|c|c|c|c|c|}
\hline & & \multicolumn{4}{|c|}{ Duration of Working at Supermarket in Years } & \multirow[t]{2}{*}{ Total } \\
\hline & & $\begin{array}{c}\text { Less than } 5 \\
\text { years }\end{array}$ & $5-10$ years & $10-15$ years & $\begin{array}{l}\text { Above } 15 \\
\text { years }\end{array}$ & \\
\hline \multirow[t]{2}{*}{ Cashiers } & Male & 2 & 2 & 1 & 1 & 6 \\
\hline & $\begin{array}{l}\text { Femal } \\
\mathrm{e}\end{array}$ & 2 & 0 & 2 & 0 & 4 \\
\hline Total & & 4 & 2 & 3 & 1 & 10 \\
\hline \multicolumn{7}{|c|}{ Subordinate Staffs } \\
\hline & Male & 3 & 2 & 2 & 0 & 7 \\
\hline & $\begin{array}{l}\text { Femal } \\
\text { e }\end{array}$ & 1 & 1 & 1 & 0 & 3 \\
\hline Total & & 4 & 3 & 3 & $\mathbf{0}$ & 10 \\
\hline
\end{tabular}

Source: Field Data 2019. 
The responses of the interviewees to the question: "How long have you been working in the supermarket outlet?" are presented in table 6. Majority, 4 cashiers and 4 Subordinate staffs had worked in supermarket outlets for less than 5 years. In addition, 3 cashiers and 3 Subordinate staffs had worked in supermarket outlets for a period ranging between 10-15 years. Lastly, 2 cashiers and 3 Subordinate staffs had worked between 5-10 years. This gives an implication that the workplace is fairly stable and employees who have worked long enough are likely to work longer as they tend to gain trust by the management. The length of the time in the workplace greatly determines the working environment as Human Resource managers would put it. This in turn reflects on the level of staff motivation that causes better returns with less likelihood of employee theft (Burke, 2016).

\section{Qualitative Data Analysis for the Supermarket Cashiers and Subordinate Staffs}

Subordinate staffs and cashiers were interviewed using interview schedules on the situational factors influencing employees' theft in supermarket outlets. They were asked open-ended questions on the various factors that relate to the effect of the prevailing opportunity, effect of organizational values and culture, finding out how employees' personal attributes contribute to theft and determining the contribution of job dissatisfaction on theft in the supermarkets within Kisumu city.

\section{Effect of Prevailing Opportunity on Employees' Theft}

The first objective of the study was to assess the effect of prevailing opportunity on employees' theft in the supermarket outlets in Kisumu City. In order to address this research objective, respondents were asked two questions.

The first question captured an opportunity as a situational factor that promotes supermarket employees theft. The responses of both cashiers and subordinate staffs were recorded and presented as study themes. Majority of the respondents indicated that the real character of employees working in the supermarket outlets can only be tested when there is an opportunity to steal. However, a few Cashiers stated that "cashiers tend to steal when there are no deterring measures to discourage them from stealing."

Majority of the respondent stated that the employees steal at their work places because there are weak systems to curb theft related cases. These loopholes put the Subordinate staffs in the greatest opportunity to allow for theft in the supermarkets. The outcome of the study depicts that supermarket theft is promoted by the availability of opportunity to steal. However, this finding differed from the research conducted by Siponen and Vance, (2010) which argued that employees rationalize their stealing habit in the retail outlets.

Similarly, this finding agreed with the assertion that KRA employees, for instance, take advantage of loopholes in the workplace to steal from their employers. This was evident in the case of the five staffs, including a KRA officer in Kisumu who colluded to steal a Toyota Prado engine from the KRA yard on display. Such cases are currently very rampant in the country as is supported by Dalton (2018).

On the question, "How does the opportunity to steal affect employees' theft in the supermarkets?" Responses from the interviewees showed that most of the respondents said that an opportunity to steal tends to make many employees to rationalize their criminal act of stealing. This because they claim that such opportunities is there to help in promoting sharing wealth with their employers. According to Subordinate 01, "An opportunity to steal at work place is a favorable moments that when not made good use of can no longer be experienced again."

In addition, majority of the participants asserted that employees' theft is a way of getting quick riches. According to Cahier 08, "When opportunity presents itself it is a sure way of getting an employee out of poverty within a very short time". Cashier 02, also said that "Most of the employees particularly subordinate staff would prefer to work in stores since there are more chances of stealing merchandize of high value for instance electronics and dispose it within a short time."

Findings of the study indicated that employees steal at their work places because there were opportunities which present itself. Weak systems to curb theft related cases were also contributing to employee theft. This is in total agreement with Omar, et al., (2016) who established that employees steal at automotive companies because there are weak systems to curb theft related cases.

In conclusion, the results to a great extent showed that the employees engaged in work place theft because they found opportunities to do so in their supermarkets. This confirms the human resource belief that the staffs will easily justify their actions however destructive they may be if there are loopholes in the system that would not give room for workplace employee accountability (IJM, 2017). 
Contribution of Organizational Values and Culture to Employees' Theft

The second objective of the study was to examine the contribution of organizational values and culture to employees' theft in supermarket outlets within Kisumu city. To address this research objective the cashiers and the Subordinate staffs were interviewed with two objective questions on the contribution of organizational values and culture to employees' theft. Based on their responses the data were computed in terms of narrative and thematic explanations.

Based on the question, "Do supermarket staffs recognize the formal organizational values and practices imposed by management?" the qualitative data were obtained and analyzed as shown. Majority of the cashiers and subordinate staffs were of the opinion that staffs do not recognize formal organizational values and practices. Subordinate 04, stated that upon recruitment, they do not undergo orientation on the do's and don'ts of the organization neither do they give manuals to guide them on their day to day activities.

According to Cashier 09, "some of the employees are always not keen in observing organizational values and practices. As a result, they engage in behaviors that are contrary to organizational norms. Through this, it becomes easier for employees to engage in workplace theft."

This finding refuted the findings of a previous study conducted by Mone, and London, (2018) which discovered that there had been massive losses incurred by the supermarkets as a result of employees' frequently picking items from the supermarket outlets without employers' authorization even though they recognized the formal organizational values and practices.

On the second question "How does the management deal with employees engaged in theft in the supermarket you work in? "Nearly all the subordinate staffs indicated that failure of an organization to set workable organizational culture and values influence employees negatively thus more likely to participate employees' theft. This is because organizational values directly influence employees' behavior. Majority of the Subordinate staffs stated that in most cases, employees who have been caught stealing are only warned but on extreme cases they are dismissed from work. Subordinate staff 02 indicated that no one has ever been subjected to criminal justice system.

Most of the cashiers indicated that some employees are untouchable no matter the kind of theft. According to cashier 04, some of the staff were brought in by 'big people' and therefore not easy to deal with them. However, staff 02 stated that some employees also steal at the directive of the bosses who are the ultimate beneficiaries. According to Subordinate Staff 01 deviant employees are punished according to laid down procedures in the human resource manual. Cashier 01 stated that code of conduct is what drives employees on day to day activities; any errant employee is always dealt according to the laid down procedures in the HR manual.

In support of this finding, (Rene (2019) indicate that these organizational values include the support orientation, rules orientation, and outcome orientation of the employees would reduce theft. Nonetheless, these findings were contrary to the findings in a related study which was done by Kumasey, et al., (2017). It found out that in most cases organizational values guide the employees on what is right or wrong and what is most important in life, which control their behavior. The findings showed that most supermarkets under study did not take into consideration enabling values and culture to shun employees from engaging in theft. These results were in absolute agreement with the survey done by Said, et al., (2017) who established that when organization to set positive organizational culture and professional values, employees' behavior positively change thus they are less likely to take part in employees' theft in the workplace.

Influence of Personal Attributes on Employees' Theft among Subordinate and Cahiers.

The third objective of the study was to find out how employees' personal attributes contributed to employees' theft in the supermarket outlets within Kisumu city. In order to address this research objective, respondents were presented with interview question: "in your opinion how can you detect employees with negative personal attributes?"

Most of the study participants stated that negative personal attributes are always seen through actions of the employee. The red flags include aggression, absenteeism, lateness, dishonest, failure to beat deadlines among other vices". Some respondents also asserted that some employees may not exert their true character with an ultimate goal to achieve. According Cashier 08, "some employees always 'hide' their character in pretense to be a good staffer to win the trust of the employer but ultimately causes damage by mainly stealing organization information and selling it to competitors. However, cashier 01 and 05 indicated that it could be hard sometimes to really understand someone personal attributes at work place. 
This result concurred with the findings of the study carried out by Moorthy, et al., (2015) which established that personal attributes and behavior of the employees can promote criminal behavior if unchecked. Secondly, with regard to the question "In your opinion, how do employees' personal attributes contribute to theft in the supermarkets?"

According to Cashiers 06, “......personal attributes such as resilience is vital even at working places. However, employees without such attribute are always quick to give up in life. They are the ones who can easily engage in employees' theft at work places. Nevertheless, employees with such remain optimistic despite hard working conditions. Without employees like this, a business will undoubtedly crumble at the first sign of trouble."

On the same note employees with negative personal attributes are most likely to engage in employee theft. Subordinate staff 01 stated that "Negativity at work place is what makes organization to lose customers. Customers who are not served well end up migrating to other supermarkets." In addition, cashier 05 indicated that "Negative personal attributes always lead to time theft due to lateness, abseentism, and malingering while at workplace and absconding duty"

\section{Contribution of Job Dissatisfaction on Employees' Theft}

The fourth objective of the research aimed at determining the contribution of job dissatisfaction on employees' theft. The interviewees were presented with research questions on the impact of job dissatisfaction on employees' theft within super market outlets. Based on their responses, data were presented in a narrative form to show the effects of job dissatisfaction on staff performance, their willingness to identify with the organization and whether rewards would motivate the staffs to boost staff performance, hence reduce employee theft.

Most respondents indicated that most employee dissatisfaction is as a result of the low pay. According to cashier 07, "Employers don't appreciate the input of employees, some deserving employees are left unrewarded while the less deserving are rewarded due to some connections." Cashier 09 in addition indicated that... "low wages with little annual increment is what demotivates the staff, on the same note there is no standard guidelines for promotion or reward".

Interestingly cashier 05 had his own view about satisfaction/dissatisfaction that employees are never satisfied. Cashier 05 therefore said that,... “... in my own sincere opinion employees continue to be dissatisfied despite being offered the best enabling environment of working”.

With regard to the question "In your opinion, do unsatisfied employees tend to commit theft in the supermarkets?" Subordinate Staff, 04 stated that, "Employees' theft behavior in the workplace is greatly increased by employee dissatisfaction because dissatisfied employees engage in withdrawal or theft behaviors to make-up for the lack of fulfillment in their career paths with a smaller section of the respondents being either unsure or not in agreement."

The findings of the study concurred with the study conducted by (Kelkar and Emilus, 2016) which discovered that dissatisfied employees are often likely to take part in counter-productive activities at the workplace as a compensation mechanism for lost fulfillment. Human resource experts agree that staff motivation greatly affects staff performance and reduces staff malpractices including theft in the workplace (IJM, 2017).

On the question: "How does employees' job dissatisfaction influence the theft in supermarkets?" Cashier 09, states that "....in reality, the unsatisfied employees tend to commit acts of property and production deviance in the workplace. This usually results in dishonesty, negligence or acts of theft by the dissatisfied staffs in the organization. However, some employees are always skeptical on the effects of job dissatisfaction on employee theft and some even felt that these two were not even remotely related, though the proportion in this category was minimal."

The study findings concurred with the findings of (Itzkovich, 2016) which discovered that in most companies, the unsatisfied employees have a habit of engaging in workplace theft.

According to Subordinate Staffs 02, “...whenever employees become dissatisfied, their behavior patterns may change and they become deviant thus their attitudes may change, leading to negative organizational behaviors such as theft." Interestingly, some other interviewees felt that; "Retail supermarkets whose employees feel that their contribution is less welcome or those who have low employee satisfaction levels almost find it natural to steal from their employers. They are good in timing their employers and quick to justify their actions." There is thus generally a strong relationship between employee's theft/fraud and employees' dissatisfaction. The very diverse views here call for a great human resource strategy to boost staff satisfaction and enhance their sense of organizational ownership to reduce theft in the workplace (Rene, 2019). 
On the question, "what steps can be taken to deal with the cases of employee theft in supermarkets?' Below is the interviewees excerpt.

Cashier 04 stated that '... It is emphasized that before efforts can be undertaken to stem employee theft, retail managers need to understand the phenomenon behind this socio-economic crime that is on the increase. This can provide insights to retail management on the nature of employee theft and who is more likely to engage in it and for what reasons."

The organizations ought to refocus their staff productivity to Indicators for performance which is a monitoring process to tame employee theft. Monitoring and evaluating staff performance requires consensus on its components and indicators.

\section{Analysis of Findings from Supermarket Management}

Qualitative data were collected by interviewing supermarket managers, and their responses recorded in theme forms for analysis. Thematic analysis is one of the most common forms of analysis within qualitative research. It emphasizes identifying, analyzing and interpreting patterns of meaning "themes" within qualitative data.

The views of supermarket managers on how situational factors impact on employees' theft in supermarket outlets in Kisumu city. These responses were collected through interviewing 10 among the targeted 13 managers of the 13 supermarket outlets in Kisumu city.

In line with the first objective that aimed at assessing the effect of prevailing opportunity to steal on employees' theft, below were managers' responses. Majority of the managers indicated that, "Most of our employees feel that they are given low wages as a result when they get little opportunity, they compromise business ethics and values to engage in stealing. Undoubtedly, availability of an opportunity to steal is considered by many employees as a major contributor to employees' theft. Some employees also have a lot of responsibility hence a slight opportunity available to steal can make them engage in theft to meet their basic needs.

Most of the managers stated that the availability of opportunity as a result of weak monitoring system and peer pressure has contributed towards promoting workplace theft. According to supermarket managers, "The employees who were faithful change whenever there is a window of opportunity to steal."

The second objective of this study was concerned about how organizational values and culture influence employees' theft in your organization. A question focusing on this organization value and culture was asked to managers and their responses consolidated in the excerpt below.

Majority of the managers indicated that in general, the time taken by an employee working in the retail outlets or any organization makes them to master the organizational values, culture and norms of operations. According to supermarket managers, "This involves understanding patterns of the working hours of their managers. Such situation to some extent contributes to rise in workplace theft because long serving employees have mastered the operational system hence find it easy to steal." Moreover, supermarket managers ascertained that there were no standardized guidelines and rules to govern employees and thus provide a window for deviance with no specific way of handling.

Third objective examined how employees' personal attributes promote their theft at work place. Views of the managers were sought with regard to this variable and the findings presented in the excerpt below.

Most of the managers indicated that "...through support orientation and acceptable ethical business practices, employees' attitude towards work change and they least engage in deviant behaviors. However, lack of support orientation and unacceptable ethical business practices just promote workplace theft in retail outlets."

With regard to the effect of job dissatisfaction on employees' theft in the supermarket outlets, the managers gave their sincere opinions which are summarized in the excerpt below. Most managers said that their organizations (supermarkets) were hiring employees on contract basis. This alone makes it difficult to have career progression.

Almost all managers stated that "Given the nature of work at the supermarkets, most employees are hired on contract terms and renewals are need based and considering the performance of an employee. As a result most of the staffs are dissatisfied and some tend to engage in theft before their time lapse". Majority of the managers also 
said that “....job dissatisfaction such as perceived long working hours, working during the holidays and weekends make employees steal to compensate themselves for additional hours worked. This has also led to deviant employee behavior, counter-productive behaviors and Lack of appreciation respectively."

\section{SUMMARY OF FINDINGS, CONCLUSIONS AND RECOMMENDATIONS}

This section presented a summary of the study findings on the situational factors influencing employees' theft in the Supermarkets within Kisumu City. Employee theft is a critical socio-economic crime that is on the increase globally. The findings are based on the responses from the completed interview schedules administered by the researcher and her research assistants. The author summarizes the discussed findings from the specific objectives of the research compared to the literature reviewed in the study. The corresponding conclusions and recommendations were then drawn from the study.

\section{Summary of the Findings}

This study used a descriptive survey design to establish the situational factors influencing employee thefts in supermarkets outlets in Kisumu city. This was determined through four main study objectives which were assessing the effect of prevailing opportunity, the effect of organizational values and culture, the effect of employees' attributes, and the contribution of job dissatisfaction on employees' theft in the supermarket outlets within Kisumu city. The data which was mainly qualitative in nature were collected using researcher administered interview schedules used on the supermarket managers, cashiers, shelf keepers, cleaners, and the watchmen in the targeted retail outlets.

The findings of the study showed that the availability of opportunity to steal is one of the main reasons why employees working in supermarkets indulge in workplace theft. Other respondents noted that employees rationalize the criminal act and give a justification. Other social economic related causes were also found to be contributing to theft in the supermarket outlets. The study established that supermarket employees steal at their workplaces because there are weak monitoring systems to curb theft-related cases. This was also encouraged by less deterrence of theft by the punishment of the offenders. As such, workplace thefts occurred, according to many respondents, due to the desire for fulfillment and could take advantage of system loopholes.

The study also examined the contribution of organizational values and culture to employees' theft in supermarket outlets. The study established that some supermarket staffs do not recognize the formal organizational values and practices imposed by the management. They believed that positive organizational values and culture hold the workforce together; making it easier for the employees to respond as a body to the fast-changing and global competition. A good number of respondents indicated that the culture of stealing was deep-rooted and no serious punitive measures were taken by management for fear of a bad reputation. In the same note, theft is promoted by the system for instance those in higher cadre use junior staff such as cleaners to steal and dispose of and they share the proceeds. Moreover, the study established that organizational values guide the employees on what is right or wrong and what is most important in life, hence greatly controls their behavior in the organizations. However, employees' theft is said to be an act that occurs with the failure of an organization to set examples through honesty, action, adherence to policies of the organization in question.

Besides, the study established that employees with negative personal attributes were more likely inclined towards engaging in criminal behavior such as theft than those who did not. The results of the study also showed that usually true that a large number of employees engage in theft in the workplace if they whenever they see their colleagues doing so without being apprehended or punished by the organization. It was also established that employees' negative personal attributes could lead to poor performance, pilfering, and poor business ethics. Furthermore, the study established that negative employee behavior like absenteeism, lateness, and dishonesty have the ultimate effect of promoting employees' theft. It was also noted that some employees camouflage their bad behavior with the ultimate goal of stealing from the organization.

Lastly, the study noted that most of the job dissatisfaction was employer-related though were of the view that no matter how work environment and motivation was, employees could still complaint of dissatisfaction. The study established that employees usually steal because they are dissatisfied, and that job dissatisfaction could be one of the reasons for employees to engage in theft at the workplace. Moreover, the study established that all times when employees become dissatisfied, their attitudes change, leading to negative behaviors, including theft. The study also established that there is a strong relationship between employee's theft/fraud and employees' dissatisfaction. Similarly, the study established that supermarkets whose employees feel that their contribution is unneeded and have low job dissatisfaction levels are more vulnerable to incidences of employee theft since they find it easier to justify theft. 


\section{Conclusion of the Study}

This study focused on four objectives; assessing the effect of prevailing opportunity, the effect of organizational values and culture, the effect of employees' attributes, and the contribution of job dissatisfaction on employees' theft in the supermarket outlets within Kisumu city. It was purely a qualitative study.

The study concluded that the availability of opportunity to steal is one of the main reasons why employees working in supermarkets indulge in workplace theft. This occurs due to the use of weak monitoring systems to curb theftrelated cases by supermarket managers. Besides, the study established that staff who steal from the workplace do not recognize the formal organizational values and practices imposed by the management. As a result, poor organization values and cultural practices have a meaningful effect on the employees in the supermarkets thus influence employees.

This, therefore, means that organizational values guide the employees on what is right or wrong and what is most important in life, hence greatly controls their behavior in the organizations. Moreover, employees with negative personal attributes for instance were more likely inclined towards engaging in criminal behavior such as theft than those who did not. Lastly, the study concluded that employees usually steal because they are dissatisfied, and this dissatisfaction is mainly contributed by employers who don't take into consideration the needs/welfare of their employees.

\section{Recommendations for Further Research}

This study endeavored to shed more light on supermarket theft, a socio-economic crime, and security problem that has nagged security and loss prevention experts for many years. It sought to add a new dimension to the understanding of staff dishonesty and employees' theft through a one-on-one encounter with the supermarket managers, cashiers, cleaners, shelf keepers, and the watchmen's experiences. The summary of major findings and conclusions has resulted in making the following recommendations for the future:

- Future researchers should conduct a comparative study on the causes of job dissatisfaction and how it contributes to employees' theft across supermarket outlets in other cities within Kenya.

- Conduct research on how employees' theft can be curbed across supermarket outlets in various towns across Kenya.

- The potential researcher should use the current study as part of their literature review and do further work on the problems explored by these studies to improve the current study and the overall perception of the workplace theft by employees across the different organizations.

\section{REFERENCES}

Adams, J. S. (1963). Wage inequities, productivity and work quality. Industrial Relations: A Journal of Economy and Society, 3(1), 9-16.

Anne Fisher and Ernie Deyle. (2019). Employee Theft by U.S. Retail Store Workers. New York: Media IP Limited.

Bérubé, H. A. (2010). An examination of alarm system deterrence and rational choice theory: the need to increase risk. Journal of Applied Security Research, 5(3), 326-381.

Bryman, A. (2016). Social research methods. Oxford university press.

Burke, R. J. (2016). Crime and corruption in organizations. In Crime and Corruption in Organizations (pp. 2386). Routledge.

Caulkin, S. (2016). Companies with a purpose beyond profit tend to make more money. Financial Times, 24.

Dalton, Nyakundi (2018). KRA Official and five others arrested over suspected theft of car engine. Nairobi: The Standard, 30 $0^{\text {th }}$ November 2018.

DeNisi, A. S., \& Murphy, K. R. (2017). Performance appraisal and performance management: 100 years of progress?. Journal of Applied Psychology, 102(3), 421.

Eck, J. E., \& Clarke, R. V. (2019). Situational Crime Prevention: Theory, Practice and Evidence. In Handbook on Crime and Deviance (pp. 355-376). Springer, Cham.

Giacalone, R.A \& Greenberg, J.D. (2017). Anti-Social Behaviour in Organisations: Acase of employee theft in Retail stores ( $p 76)$. Miami National Economic Survey, Mellisa Ltd.

Gold, C. M. (2016). Staff Management. Nonprofit Management: A Social Justice Approach, 73.

Hansen, M. W., Langevang, T., Rutashobya, L., \& Urassa, G. (2018). Coping with the African business environment: enterprise strategy in response to institutional uncertainty in Tanzania. Journal of African Business, 19(1), 1-26.

Itzkovich, Y., \& Heilbrunn, S. (2016). The role of co-workers' solidarity as an antecedent of incivility and deviant 
behavior in organizations. Deviant Behavior, 37(8), 861-876.

Kenya National Bureau of Statistics (KNBS, 2019).

Knežević, B., Delić, M., \& Jurčević, M. (2016). Detecting and Preventing Employees'theft in Retail. Trade Perspectives 2016 Safety, security, privacy and loyalty PERSPEKTIVE TRGOVINE 2016. Sigurnost, privatnost i lojalnost, 90

Krejcie, R. V., \& Morgan, D. W. (1970). Determining sample sizes for research activities. Educational and Psychological Measurement, 607-610.

Kumasey, A. S., Bawole, J. N., \& Hossain, F. (2017). Organizational commitment of public service employees in Ghana: do codes of ethics matter? International Review of Administrative Sciences, 83(1_suppl), 59-77.

Lee, H. E., Kim, H. R., \& Park, J. S. (2013). Work-related risk factors for workplace violence among Korean employees. Journal of occupational health, 13-0082.

Lind, K., \& Kääriäinen, J. (2018). Cheating and stealing to finance gambling: analysis of screening data from a problem gambling self-help program. Journal of Gambling Issues, (39).

Mone, E. M., \& London, M. (2018). Employee engagement through effective performance management: A practical guide for managers. Routledge.

Moorthy, M. K., Seetharaman, A., Jaffar, N., \& Foong, Y. P. (2014). Employee perceptions of workplace theft behavior: A study among supermarket retail employees in Malaysia. Ethics \& Behavior, 25(1), 61-85.

Nardi, P. M. (2018). Doing survey research: A guide to quantitative methods. Routledge.

Nzuve, S. N., \& Njeru, L. K. (2013). Perceived factors affecting performance management among local authorities in Kenya: a case of the city council of Nairobi.

Pfeffer, J., \& Veiga, J. F. (2009). Putting people first for organizational success. Academy of Management Perspectives, 13(2), 37-48.

Rene, Chun (2019). Criminal Tendencies: Workplace Theft is on the Rise. The Atlantic, March 2019 Issue.

Said, J., Alam, M. M., Ramli, M., \& Rafidi, M. (2017). Integrating ethical values into fraud triangle theory in assessing employee fraud: Evidence from the Malaysian banking industry. Journal of International Studies, 10(2), 170-184.

Siegel, L. J., \& McCormick, C. (2006). Criminology in Canada: Theories. Patterns, and.

Scoones, I. (2018). 2.14 Land grabbing. Companion to Environmental Studies, 214.

Siponen, M., \& Vance, A. (2010). Neutralization: new insights into the problem of employee information systems security policy violations. MIS quarterly, 487-502.

Tracy, S. J. (2019). Qualitative research methods: Collecting evidence, crafting analysis, communicating impact. John Wiley \& Sons. 